\title{
INFLUÊNCIA DAS CARACTERÍSTICAS DO ITABIRITO CONCENTRADO NO DESEMPENHO DO PROCESSO DE SINTERIZAÇÃO*
}

Lindaura de Souza Cândido d'Avila ${ }^{1}$ Railson Nogueira de Azevedo ${ }^{2}$ Maurício Covcevich Bagatini ${ }^{3}$ José Sérgio Santana de Castro ${ }^{4}$

\section{Resumo}

O presente trabalho é parte de um estudo mais abrangente que busca o desenvolvimento da mistura de diferentes tipos de minérios de ferro para a maximização da produtividade na sinterização. Essa etapa do estudo teve o intuito de avaliar as diferentes características do minério de ferro itabirítico e sua influência na produtividade da sinterização em escala piloto. Inicialmente foi realizada a caracterização dos minérios de ferro hematítico e itabirítico oriundos do Quadrilátero Ferrífero. Em seguida, foram testadas em escala piloto misturas de minério de ferro com proporções variadas de minério hematítico e itabirítico. A partir dos resultados de produtividade e de qualidade do sínter obtido foi possível avaliar o efeito do minério itabirítico na mistura de sinterização. Tais resultados indicam diferentes desempenhos desses parâmetros na unidade piloto de sinterização.

Palavras-chave: Minérios de ferro; Sinterização; Produtividade; Qualidade do sínter.

\section{INFLUENCE OF CONCENTRATED ITABIRITE CHARACTERISTICS ON THE PERFORMANCE OF THE PROCESS OF THE SINTER PLANT}

\section{Abstract}

This work is part of a larger study that seeks the development of the mixture of different types of iron ores to the sintering productivity maximization. This stage of the study was designed to evaluate the different characteristics of itabirite iron ore and their influence on the productivity of the sintering on a pilot scale. Initially it was made the characterization of the hematite and itabirite iron ores from the Quadrilatero Ferrifero. Then mixtures of iron ore with varied proportions of hematite and itabirite ores were tested on a pilot scale. From the productivity and quality of sinter results obtained, it was possible to evaluate the effect of the itabirite ore on the sintering mixture. These results indicate different performances of these parameters in the pilot sintering plant.

Keywords: Iron ore; Sintering; Productivity; Quality of sinter.

1 Engenheira Metalurgista, Mestranda do Programa de Pós-Graduação em Eng. de Minas, Metalúrgica e de Materiais, PPGEM, UFMG; Assessora Técnica da Área de Sinterizações da Gerdau Usina Ouro Branco, Ouro Branco, MG, Brasil.

2 Técnico Metalurgista, Assessor Técnico da Área de Sinterizações da Gerdau Usina Ouro Branco, Ouro Branco, MG, Brasil.

3 Professor, nas Áreas de Siderurgia, Depto. de Eng. de Minas, Metalúrgica e de Materiais, PPGEM, UFMG, Belo Horizonte, MG, Brasil.

4 Engenheiro Metalurgista, Gerente da Área de Sinterizações da Gerdau Usina Ouro Branco, Ouro Branco, MG, Brasil. 


\section{INTRODUÇÃO}

No Quadrilátero Ferrífero estão localizadas grandes reservas de minério de ferro. Estes podem ser classificados em dois grupos principais: os itabiríticos, minérios de mais baixo teor de ferro, mais heterogêneos, e os hematíticos de alto teor, quimicamente mais homogêneos, ricos em óxidos de ferro.

Nos últimos anos as jazidas de minérios de ferro vêm apresentando fortes alterações no perfil do ROM (Run of Mine) que alimenta as usinas de beneficiamento. A relação hematita/itabirito (HE/IT) nos ROMs, ao longo do tempo vem se tornando cada vez menor, sendo que esta redução é resultado direto de um ROM mais itabirítico se comparado à última década. A inversão desta relação é uma tendência natural das reservas ou jazidas com a evolução da lavra, e com aumento da participação dos itabiritos na matriz de minérios de ferro que são alimentadas nas usinas de beneficiamento, torna-se cada vez mais importante conhecer o comportamento desses minérios de ferro visando manter a produtividade das sinterizações.

A extração de minérios que antes era prioritariamente de minérios hematíticos compacto mudou, dando lugar para também as hematitas friáveis, itabiritos ricos e em um passo seguinte os itabiritos pobres e hidratados. Com o decréscimo das minas de minérios hematíticos (mudando de $100 \%$ de hematita para a participação significativa do itabirito) e maiores restrições ambientais, ficou claro que, a partir da última década a especificação de finos de minérios de ferro para sinterização até então praticada, não deve ser a mesma.

Neste contexto, é evidente a necessidade de conhecer as características mineralógicas, microestruturais e de aglomeração dos minérios de ferro individuais, visando à obtenção de misturas mais adequadas à produtividade e que atenda as características físicas, químicas e metalúrgicas requeridas para o sínter produto para uso nos altos-fornos.

Dentro desta realidade de elevação do uso de minério de ferro itabirítico, este trabalho teve o objetivo de investigar as características e o desempenho em escala piloto de sinterização desse minério de ferro.

\section{MATERIAIS E MÉTODOS}

\subsection{Caracterização dos Minérios de Ferro}

As amostras de sinter feed estudadas foram coletadas em áreas de mineração do Quadrilátero Ferrífero e foram caracterizadas como sendo do tipo: hematita friável (HeFr) e itabirito friável pobre (ItFr).

A amostra do minério de ferro hematita friável foi gerada utilizando a seguinte rota de processo: britagem em $8,0 \mathrm{~mm}$, peneiramento a seco para a obtenção de um subproduto $-8,00 \mathrm{~mm}$. Em seguida, a fração $-8,00 \mathrm{~mm}$ foi submetida ao peneiramento a úmido e deslamagem, obtendo produtos de 0,010 a $8,00 \mathrm{~mm}, 1,00$ a $8,00 \mathrm{~mm}$, 0,149 a $1,00 \mathrm{~mm}$ e $-0,149 \mathrm{~mm}$.

A amostra do minério de itabirito friável foi concentrada em planta de beneficiamento utilizando processos gravíticos e flotação, obtendo produto $-8,00 \mathrm{~mm}, 1,00$ a $8,00 \mathrm{~mm}$, 0,149 a $1,00 \mathrm{~mm}$ e $-0,149 \mathrm{~mm}$.

Para a caracterização dos minérios de ferro foram realizadas análises químicas, granulométricas, mineralógicas e microestruturais, através das seguintes técnicas: fluorescência de raios $\mathrm{x}$, via úmida, série de malhas Tyler e microscopia óptica. Para 
caracterização mineralógica e microestrutural foi utilizado o microscópio óptico de luz transmitida e refletida com captura de imagem.

Para identificação das características físicas dos minérios de ferro foram realizadas as seguintes análises: porosidade por meio de picnômetro, avaliação do poder de aglomeração a frio e capacidade de umidificação pelo efeito da pressão capilar dos minérios de ferro. O poder de aglomeração a frio foi avaliado com o auxílio do Índice de Granulação (IG), cuja fórmula matemática está descrita abaixo:

$$
I G=\left(\frac{A-D}{A}\right) \times 100
$$

Onde:

A (partícula primária): percentual em massa da fração $-0,500 \mathrm{~mm}$ antes da homogeneização da amostra;

B: percentual em massa da fração $-0,500 \mathrm{~mm}$ após o peneiramento úmido da quase partícula.

A capacidade de umidificação foi definida como o teor máximo de água absorvido pela amostra de minério de ferro por unidade de massa. A água em contato com a amostra de minério de ferro dentro da coluna é absorvida sob o efeito de pressão capilar. A amostra seca do minério de ferro na fração $+1,00 \mathrm{~mm}$ é depositada no tubo de ensaio com a extremidade fechada por tela e filtro de papel para o material não vazar. O tubo de ensaio com a extremidade em contato com a água está conectado em uma balança digital que mede a quantidade de água absorvida. É feita a leitura da medição de absorção de água a cada 10s até que a amostra de minério de ferro sature em água. As medidas são feitas em triplicatas e o resultado final é a média aritmética dos três valores obtidos. A equação utilizada para calcular a capacidade de umidificação (CU) está descrita abaixo:

$$
\mathrm{CU}=\frac{\mathrm{Ma}}{\mathrm{Mm}} \times 100
$$

Onde:

Ma: massa de água absorvida;

$\mathrm{Mm}$ : massa de minério da amostra.

\subsection{Testes em Sinterização Piloto}

Foram realizados testes de sinterabilidade em planta piloto com minérios de ferro individuais e misturas e a avaliação da qualidade do sínteres produzidos.

Para os testes em escala piloto, a metodologia Francesa foi empregada para realização das queimas. Após os testes na sinterização piloto foram determinados os principais parâmetros de desempenho como: consumo de combustível, produtividade e resistência mecânica (Tumbler Test - ISO 3271) dos sínteres. Além disso, foram feitas análises químicas e granulométricas dos sínteres produzidos.

Foram feitas sete misturas para os ensaios, os quais foram realizados em triplicata na sinterização piloto. Foram realizados testes com minérios de ferro individual e misturas com a hematita friável e itabirito concentrado friável em diferentes índices de participação conforme Tabela 1. 
Tabela 1. Composição das misturas de minérios

\begin{tabular}{|l|c|c|c|c|c|c|c|}
\hline \multirow{2}{*}{ Minérios } & \multicolumn{7}{|c|}{ Mistura de minérios (\%) } \\
\cline { 2 - 8 } & M1 & M2 & M3 & M4 & M5 & M6 & M7 \\
\hline HeFr & 100 & 0 & 90,00 & 80,00 & 70,00 & 60,00 & 50,00 \\
\hline ItFr & 0,00 & 100 & 10,00 & 20,00 & 30,00 & 40,00 & 50,00 \\
\hline
\end{tabular}

$\mathrm{Na}$ Tabela 2, estão apresentadas as premissas de qualidade química objetivada para o sínter produto e demais parâmetros do teste na sinterização piloto.

Tabela 2. Características químicas objetivadas para o sínter e principais parâmetros de processo.

\begin{tabular}{|c|c|}
\hline Parâmetro & Referência \\
\hline Basicidade $\left(\mathrm{CaO} / \mathrm{SiO}_{2}\right)$ do sínter & 1,75 \\
\hline Teor de MgO do sínter (M1 e M2) & $1,45 \%$ \\
\hline $\begin{array}{l}\text { Teor de MgO do sínter } \\
\text { (M3,M4,M5,M6,M7) }\end{array}$ & $1,55 \%$ \\
\hline Teor de $\mathrm{SiO}_{2}$ do sínter (M1 e M2) & $6,65 \%$ \\
\hline $\begin{array}{c}\text { Teor de } \mathrm{SiO}_{2} \text { do sínter } \\
(\mathrm{M} 3, \mathrm{M} 4, \mathrm{M} 5, \mathrm{M} 6, \mathrm{M} 7) \\
\end{array}$ & $5,50 \%$ \\
\hline Teores de $\mathrm{Al}_{2} \mathrm{O}_{3}, \mathrm{Mn}$ e $\mathrm{P}$ & Residuais de cada mistura \\
\hline Fonte de $\mathrm{MgO}$ & dolomita \\
\hline Cal na mistura parcial & $5,00 \%$ \\
\hline Coque na mistura a sinterizar & Retorno balanceado \\
\hline Umidade da mistura & $7,30 \%$ \\
\hline Altura da camada da máquina & $500 \mathrm{~mm}$ \\
\hline Depressão de ignição & $900 \mathrm{mmH}_{2} \mathrm{O}$ \\
\hline Depressão de queima & $1.200 \mathrm{mmH}_{2} \mathrm{O}$ \\
\hline Depressão de resfriamento & $700 \mathrm{mmH}_{2} \mathrm{O}$ \\
\hline Massa de falsa grelha & $4,5 \mathrm{~kg}$ \\
\hline Tempo de ignição & 1 minuto \\
\hline
\end{tabular}

A Tabela 3 apresenta o planejamento experimental das queimas com a porcentagem de cada matéria-prima que compôs cada uma das misturas preparadas (porcentagem na mistura total). 
Tabela 3. Porcentagem das matérias-primas que compõem cada uma das misturas (porcentagem na mistura total).

\begin{tabular}{|c|c|c|c|c|c|c|c|}
\hline $\begin{array}{c}\text { Mistura a } \\
\text { Sinterizar }\end{array}$ & $\begin{array}{c}\text { M1 } \\
(\mathbf{1 0 0})\end{array}$ & $\begin{array}{c}\text { M2 } \\
(\mathbf{1 0 0})\end{array}$ & $\begin{array}{c}\text { M3 } \\
\mathbf{( 9 0 / 1 0 )}\end{array}$ & $\begin{array}{c}\text { M4 } \\
(\mathbf{8 0 / 2 0})\end{array}$ & $\begin{array}{c}\text { M5 } \\
(\mathbf{7 0 / 3 0 )}\end{array}$ & $\begin{array}{c}\text { M6 } \\
(\mathbf{6 0 / 4 0 )}\end{array}$ & $\begin{array}{c}\text { M7 } \\
(\mathbf{5 0 / 5 0 )}\end{array}$ \\
\hline MFHe (hematita) & 47,12 & - & 44,73 & 39,81 & 34,95 & 30,05 & 25,08 \\
\hline MFIt (itabirito) & - & 50,59 & 5,30 & 10,61 & 15,93 & 21,24 & 26,48 \\
\hline Calcário & 4,97 & 4,90 & 1,56 & 1,58 & 1,54 & 1,55 & 1,75 \\
\hline Dolomita & 4,49 & 4,13 & 5,18 & 5,16 & 5,14 & 5,11 & 5,08 \\
\hline Cal virgem & 3,57 & 3,57 & 3,62 & 3,62 & 3,62 & 3,62 & 3,62 \\
\hline Coque/Antracito & 3,60 & 3,60 & 3,64 & 3,60 & 3,60 & 3,60 & 3,60 \\
\hline Degradado & 8,21 & 8,21 & 8,17 & 8,17 & 8,18 & 8,19 & 8,16 \\
\hline Quartzito & 3,03 & - & 2,97 & 2,63 & 2,22 & 1,81 & 1,40 \\
\hline Retorno & 25,00 & 25,00 & 24,00 & 24,00 & 24,00 & 24,00 & 24,00 \\
\hline Pó Coletor & - & - & 0,31 & 0,31 & 0,31 & 0,31 & 0,31 \\
\hline Carepa & - & - & 0,52 & 0,51 & 0,51 & 0,51 & 0,51 \\
\hline
\end{tabular}

Como combustível, foram utilizados coque e antracito $(55 \%$ de coque $+45 \%$ de antracito). O percentual de sílica adicionada via quartzito nas misturas $M 1, M 3, M 4$, $\mathrm{M} 5, \mathrm{M} 6$ e M7 foi definido de maneira a manter o mesmo patamar de $\mathrm{SiO}_{2}$ no sínter produto. A fração $+1,00 \mathrm{~mm}$ da mistura de minérios para mistura $\mathrm{M} 1$ foi de $34,60 \%$, para M2 foi de 29,99\% e para as demais M-03, M-04, M-05, M-06 e M-07 foram mantidas em $39,00 \% \pm 1 \mathrm{pp}$.

\section{RESULTADOS E DISCUSSÃO}

\subsection{Caracterização dos Minérios de Ferro}

$\mathrm{Na}$ Tabela 4 estão apresentados os resultados das análises químicas e granulométricas dos minérios de ferro avaliados. O minério de ferro hematítico apresentou, no resultado de análise global, baixos níveis de contaminantes, com sílica de $0,92 \%$. No entanto, esse minério apresenta granulometria relativamente fina, desfavorável à permeabilidade do leito de sinterização, representado pela fração $+1,0 \mathrm{~mm}$ em $34,60 \%$ e fração $-0,149 \mathrm{~mm}$ em 39,41\%.

O minério de ferro itabirítico, por sua vez, apresentou teores mais elevados de contaminantes como sílica e manganês. O sinter feed desse minério também apresenta granulometria considerada fina, representada pela fração $+1,0 \mathrm{~mm}$ em $29,99 \%$ e $-0,149 \mathrm{~mm}$ em $42,54 \%$. 
Tabela 4. Resultados de análises químicas e granulométricas dos minérios de ferro.

\begin{tabular}{|l|c|c|c|c|c|c|c|c|c|c|}
\hline \multicolumn{10}{|c|}{ Análises Químicas (\% em massa) } \\
\hline Minério & $\mathbf{F e T}$ & $\mathbf{C a O}$ & $\mathbf{S i O}_{2}$ & $\mathbf{A l}_{2} \mathrm{O}_{3}$ & $\mathbf{M g O}$ & $\mathbf{M n T}$ & $\mathbf{P}$ & $\mathbf{F e O}$ & $\mathrm{TiO}_{2}$ & $\mathbf{P P C}$ \\
\hline $\mathrm{HeFr}$ & 68,29 & 0,001 & 0,92 & 0,57 & 0,07 & 0,22 & 0,017 & 1,57 & 0,047 & 0,29 \\
\hline ItFr & 62,73 & 0,150 & 6,41 & 0,61 & 0,18 & 0,61 & 0,049 & 4,28 & 0,028 & 1,90 \\
\hline \multicolumn{10}{|c|}{ Análises Granulométricas (\% em massa) } \\
\hline Minério & $\mathbf{8 , 0 0}$ & $\mathbf{6 , 3 5}$ & $\mathbf{2 , 8 3}$ & $\mathbf{1 , 0 0}$ & $\mathbf{0 , 5 0 0}$ & $\mathbf{0 , 1 4 9}$ & $\mathbf{0 , 1 0 5}$ & $\mathbf{0 , 0 4 4}$ & $<\mathbf{0 , 0 4 4}$ & TM \\
\hline HeFr & 4,24 & 2,05 & 14,50 & 13,81 & 10,67 & 15,32 & 1,51 & 18,06 & 19,84 & 1,57 \\
\hline ItFr & 1,04 & 1,49 & 12,24 & 15,22 & 7,31 & 20,15 & 4,78 & 31,04 & 6,72 & 1,16 \\
\hline
\end{tabular}

A caracterização mineralógica do minério de ferro contribui para a compreensão dos fenômenos de aglomeração a frio, de sinterização, das propriedades do sínter e o seu comportamento no processo de redução em altos-fornos. Os resultados de caracterização mineralógica e microestrutural (Figura 1) demonstram as diferenças entre os minérios de ferro.

A fotomicrografia (a) apresenta partículas de hematita lobular (forma regular e cristais compactos) e de goethita mista com hematita. Esse minério tem classificação mineralógica hematítico lobular, granular e tabular. Caracteriza-se pela presença de hematita lobular, granular e tabular, sendo a primeira mais abundante. Normalmente a hematita tabular está presente em percentagem inferior.

A fotomicrografia (b) apresenta partículas mistas de martita com magnetita (geralmente porosa) e partículas de goethita (material amorfo com textura porosa). Esse minério de ferro caracteriza-se pela presença de magnetita, hematita, goethita e martita, sendo a primeira mais abundante. Normalmente a martita está presente em percentagem inferior. $O$ mineral contaminante é principalmente o quartzo.
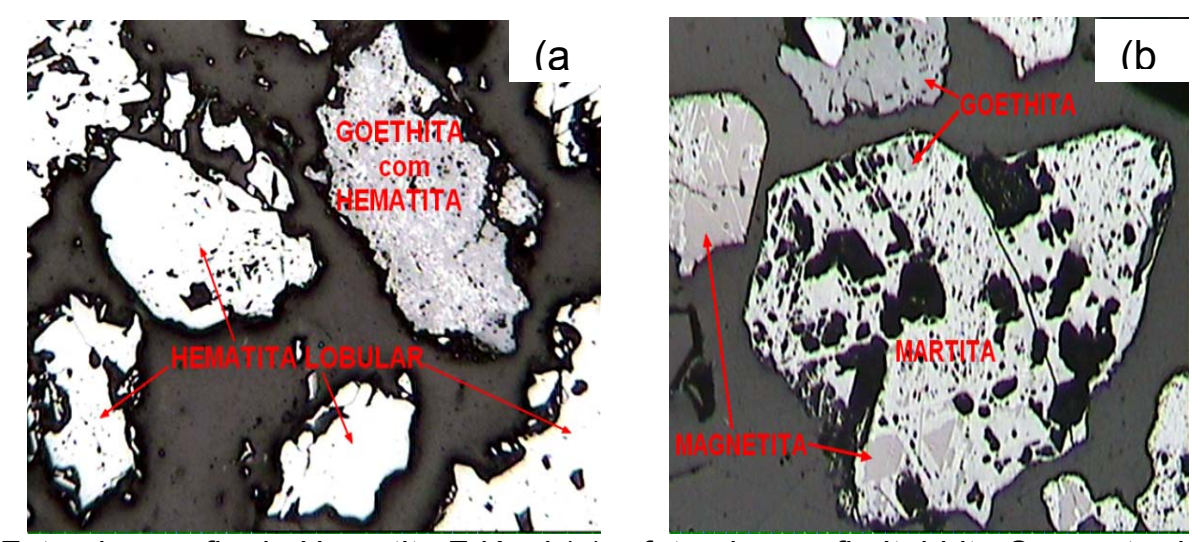

Figura 1. Fotomicrografia da Hematita Friável (a) e fotomicrografia Itabirito Concentrado Friável (b).

Na Figura 2 estão apresentados os resultados dos ensaios de avaliação da aglomeração a frio dos minérios e suas características físicas. Tais ensaios demonstraram diferenças significativas entre os minérios, as quais estão de acordo com os resultados encontrados pelas análises de caracterização realizadas.

O minério de ferro itabirítico apresentou maior capacidade de absorção de água, representada pela capacidade de umidificação com índice de $10,78 \%$ em relação ao minério de ferro hematítico com índice de 9,09\%. Com relação à avaliação do índice de porosidade o minério de ferro itabirítico obteve resultado superior com índice de $17,50 \%$ em comparação ao minério de ferro hematítico com índice de $14,17 \%$. 
O índice de aglomeração a frio foi à diferença mais expressiva. O índice de granulação do minério de ferro hematítico foi de $75,66 \%$, o qual é bastante superior, quando comparado ao minério de ferro itabirítico com índice de $17,60 \%$. Este resultado possivelmente se deu pela diferença na mineralogia dos minérios, sendo o hematítico menos poroso em função de sua estrutura.

Ainda quanto à aglomeração a frio (obtida através do índice de granulação), foi possível observar que se teve diferenças quanto à capacidade que eles têm de formar micropelotas ou grânulos quando providos de certa umidade e submetidos a uma etapa de misturamento (micropelotização). Essa propriedade também pode ser influenciada pela porosidade, que aumenta a absorção de água para a formação de um filme em torno da partícula, o que promove maior retenção de umidade.

Para o minério de ferro itabirítico, a umidade em que o teste de aglomeração a frio foi realizado $(6,5 \%)$ pode ter influenciado o resultado, uma vez, que este minério de ferro provavelmente necessita de uma umidade maior para um melhor desempenho no processo de aglomeração.
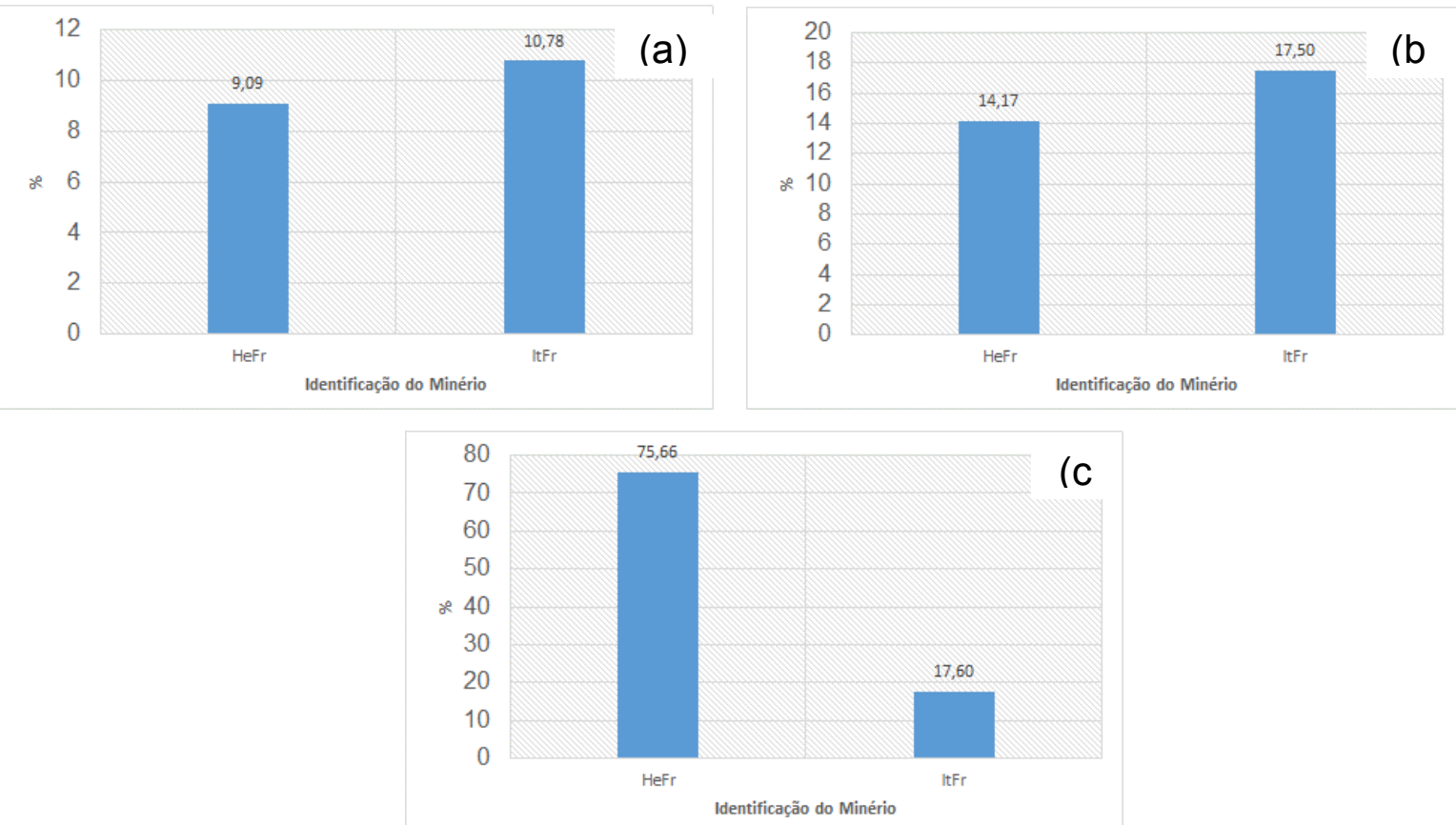

Figura 2. Capacidade de umidificação (capilaridade) (a), porosidade (b) e aglomeração a frio obtida através do índice de granulação (c) para os minérios de ferro avaliados.

\subsection{Testes de Sinterização em Escala Piloto}

Na Figura 3 estão apresentados os resultados dos principais parâmetros de desempenho obtidos nos ensaios em planta piloto de sinterização: consumo de combustível, produtividade e resistência mecânica dos sínteres produzidos.

Os resultados dos índices de desempenho em questão apontam para uma significativa influência das características dos minérios de ferro testados. De acordo com os resultados apresentados na Figura 3 (a), a produtividade apresentou inferior quando se utilizou $100 \%$ de minério itabirito concentrado nos testes individuais. Nota-se que existe uma forte tendência de perda de produtividade quando se aumenta a participação do concentrado de minério itabirítico na mistura a sinterizar, conforme Figura 4 (a). Esse fato pode ser explicado pela perda de permeabilidade do leito com reflexo na queda do tempo de sinterização, visto que a capacidade de 
aglomeração a frio da hematita friável apresentou-se superior ao concentrado de itabirito.

Quanto aos resultados do consumo de combustível, também foram observadas variações significativas. Verificou-se que quando se utilizou os minérios hematítico e itabirítico individualmente, foram obtidos consumos superiores em relação às outras misturas avaliadas.

A qualidade física dos sínteres, apresentada na Figura 3 (c), mostra os resultados do ensaio de tamboramento realizado para cada mistura. Observa-se que, quando se utilizou os minérios individualmente, este índice ficou acima de $80 \%$, sendo estes superiores quando comparados às outras misturas avaliadas.

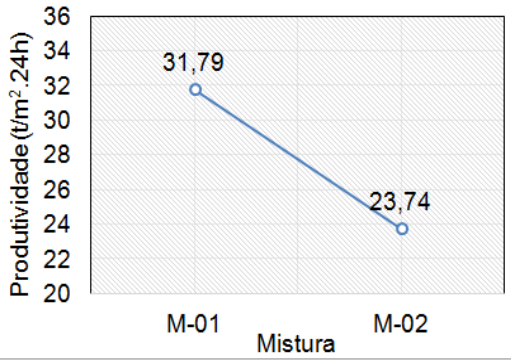

(a) Produtividade

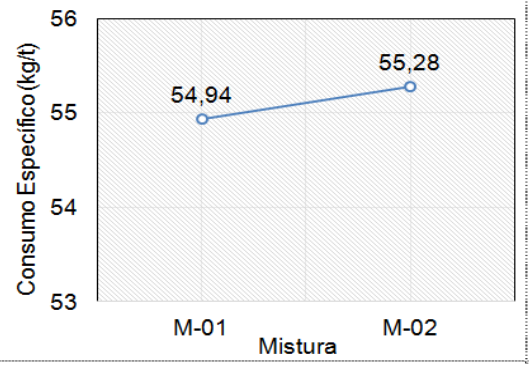

(b) Consumo de Combustível

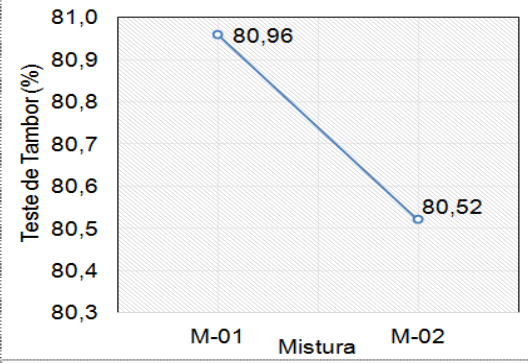

(c) Tamboramento ISO 3271 $(+6,3 \mathrm{~mm})$

Figura 3. Principais parâmetros de desempenho obtidos nos ensaios com misturas utilizando os minérios individualmente.

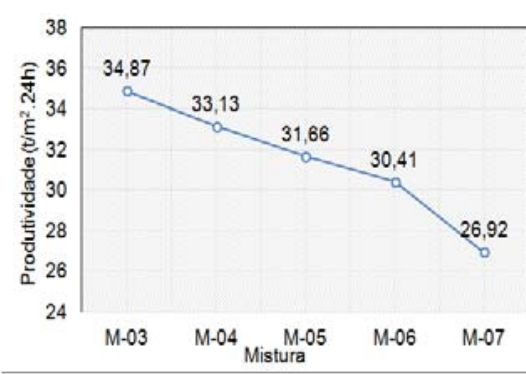

(a) Produtividade

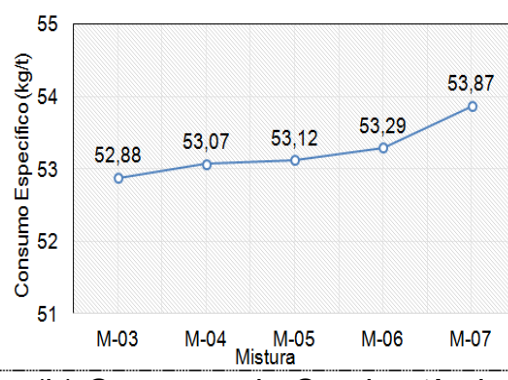

(b) Consumo de Combustível

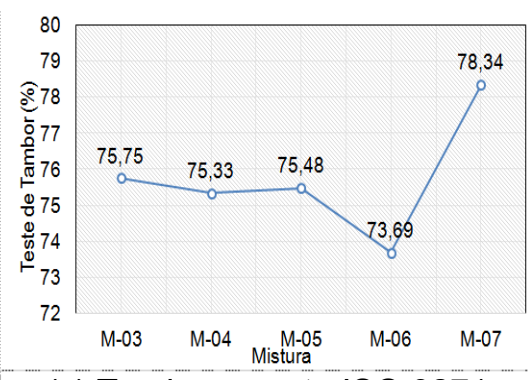

(c) Tamboramento ISO 3271 $(+6,3 \mathrm{~mm})$

Figura 4. Principais parâmetros de desempenho obtidos nos ensaios com misturas com variações na proporção do minério de ferro itabirítico.

$\mathrm{Na}$ Tabela 5 estão apresentados os resultados das análises químicas e granulométricas de cada sínter produto gerado em cada um dos testes realizados na sinterização piloto.

O sínter produzido apresentou uma variação no teor de $\mathrm{SiO}_{2}$ das misturas $\mathrm{M} 1$ e $\mathrm{M} 2$ de $6,95 \%$ e $7,18 \%$, respectivamente. Para as demais misturas houve uma variação de $5,08 \%$ a $5,91 \%$. Os resultados de granulometria apresentados mostraram um tamanho médio de partículas das misturas M1 e M2 de 25,15mm e 25,79mm, respectivamente. Para as demais misturas houve uma variação de $26,71 \mathrm{~mm}$ a $27,48 \mathrm{~mm}$. Essas variações de qualidade foram consideradas aceitáveis para as análises desse trabalho. 
Tabela 5. Qualidade química e granulométrica de cada sínter produto.

\begin{tabular}{|c|c|c|c|c|c|c|c|}
\hline Análise Química (\%) & M1 & M2 & M3 & M4 & M5 & M6 & M7 \\
\hline Fe Total & 56,25 & 55,42 & 58,44 & 58,30 & 58,48 & 57,95 & 57,18 \\
\hline $\mathrm{FeO}$ & 6,03 & 6,05 & 7,15 & 6,68 & 7,26 & 6,87 & 6,84 \\
\hline $\mathrm{SiO}_{2}$ & 7,18 & 6,95 & 5,08 & 5,21 & 5,52 & 5,90 & 5,91 \\
\hline $\mathrm{Al}_{2} \mathrm{O}_{3}$ & 0,91 & 0,90 & 0,90 & 1,00 & 1,00 & 1,03 & 1,23 \\
\hline $\mathrm{CaO}$ & 10,46 & 11,28 & 9,13 & 9,16 & 9,16 & 9,04 & 9,56 \\
\hline $\mathrm{MgO}$ & 1,39 & 1,42 & 1,54 & 1,38 & 1,41 & 1,33 & 1,43 \\
\hline Mn & 0,26 & 0,65 & 0,36 & 0,44 & 0,45 & 0,48 & 0,58 \\
\hline $\mathbf{P}$ & 0,036 & 0,053 & 0,024 & 0,034 & 0,035 & 0,039 & 0,043 \\
\hline Basicidade & 1,46 & 1,62 & 1,80 & 1,76 & 1,66 & 1,53 & 1,62 \\
\hline Granulometria & M1 & M2 & M2 & M3 & M4 & M5 & M6 \\
\hline $50,0 \mathrm{~mm}$ & 6,32 & 9,79 & 9,07 & 9,82 & 9,34 & 10,35 & 9,69 \\
\hline $25,0 \mathrm{~mm}$ & 36,14 & 31,17 & 40,87 & 37,27 & 38,39 & 39,29 & 38,68 \\
\hline $10,0 \mathrm{~mm}$ & 33,91 & 36,09 & 26,43 & 26,86 & 26,88 & 25,61 & 27,36 \\
\hline $5,0 \mathrm{~mm}$ & 22,49 & 21,94 & 22,72 & 24,97 & 24,32 & 23,68 & 23,12 \\
\hline$-5,0 \mathrm{~mm}$ & 1,14 & 1,01 & 0,92 & 1,08 & 1,08 & 1,08 & 1,14 \\
\hline Tamanho Médio (mm) & 25,15 & 25,79 & 27,34 & 26,71 & 26,78 & 27,48 & 27,11 \\
\hline
\end{tabular}

\section{CONCLUSÃO}

Os resultados de caracterização demonstraram que os minérios em estudo apresentam distinções químicas e mineralógicas. No minério de ferro hematítico, observou-se que a hematita lobular é a fase mineral predominante, enquanto que no minério itabirítico, a principal fase encontrada é a magnetita. Também foram observadas diferenças significativas quanto às características físicas desses minérios. Comparativamente ao minério hematítico, minério itabirítico apresentou maiores valores de porosidade, o que deve explicar o seu menor desempenho de aglomeração a frio e maior capacidade de umidificação nas condições testadas.

Observou-se também que o desempenho do processo de sinterização foi influenciado pelas características intrínsecas dos minérios, tais como, mineralogia e microestrutura e características físicas. Os melhores níveis de produtividade obtidos na sinterização piloto foram com o minério de ferro hematítico individual. Esse comportamento pode ser explicado pelo favorecimento da permeabilidade do leito ao se utilizar o minério hematítico, que apresentou um melhor índice de aglomeração a frio.

Os resultados obtidos nesse trabalho permitiram concluir que o conhecimento prévio das características intrínsecas da mistura de minérios a sinterizar, que são definidos a partir do ROM e das rotas de processo estabelecidas no beneficiamento do sinter feed, contribuem para o conhecimento do desempenho na sinterização. Nesse sentido, esse conhecimento poderá promover a otimização de parâmetros utilizados 
nos processos de sinterização e, consequentemente, um melhor desempenho de produtividade e maior qualidade física do sínter produzido. Esse tipo de abordagem permite verificar a influência novos tipos de minério no processo de sinterização minimizando os efeitos do mesmo quando usado em escala industrial.

\section{Agradecimentos}

Os autores agradecem o apoio da CAPES-PROEX, CNPq, FAPEMIG e a Gerdau Usina Ouro Branco para a realização do presente trabalho.

\section{BIBLIOGRAFIA}

1 Araújo Filho, G. M. Caracterização de misturas para sinterização. Dissertação de Mestrado aprovada pelo CPGEM/EEUFMG, Belo Horizonte, 1984.

2 Goldring, D. C, Fray, T. A. - Characterization of iron ores for production of high quality sinter. - Ironmaking and Steelmaking, 1989, Vol. 16, №2.

3 Azevedo, R. N; Davila, L. S. C. et al. Curso de Sinterização. GERDAU OURO BRANCO, MG, Brasil, p. 32-66, 2013.

4 Costa, J.C.V. Caracterização do itabirito dolomítico da Mina de Conceição, visando aproveitamento como matéria-prima na siderurgia. Belo Horizonte: Escola de Engenharia da UFMG, 2013. (Dissertação, Mestrado em Engenharia Melatúrgica).

5 Honorato, E.P; Rangel, Najar, F. J. - Curso: Utilização do minério de ferro na siderurgia. USIMINAS, Ipatinga, MG, Brasil, 1993. p.6-27.

6 Moloney, W. V, Lennox, N. - Effect of Modified Mixing and Moisture on sintering - New Castle Steel Works - BHP Technical Bulletin - Vol. 25, №1 - May 1981.

7 Padula, V. P. Caracterização tecnológica de um sinter feed hematítico contendo diferentes proporções e tipos de sílica nas frações aderentes, intermediárias e nucleantes. Ouro Preto. Programa de Pós-Graduação em Engenharia Mineral (PPGEM), 2009. (Dissertação de mestrado).

8 Vieira, C.B; Rosière, C. A; Pena, E. Q; Seshadri V.; Assis, P.S. - Avaliação técnica de minérios de ferro para sinterização nas siderúrgicas e minerações brasileiras: Uma análise crítica. REM, Esc. de Minas de Ouro Preto, 56(2), 97-102, 852003.

9 Rosière, C. A. A recristalização do minério de ferro da jazida do Pico do Itabirito no Quadrilátero Ferrífero e suas implicações genéticas. In: II Simpósio de Geologia de Minas Gerais, 1983, Belo Horizonte. Boletim da SGB - Núcleo Minas Gerais. Belo horizonte: SBG-MG,1983. v. 3. p.173-186. 